\title{
Comparación de dos productos botánicos vrs. un sintético para control de mosca blanca en cultivo de melón
}

Blanca Esmeralda Zúniga *,Dunia Lizeth Núñez*, Liliam Carina Marroquín **

\section{RESUMEN}

Con el objetivo de identificar y señalar productos botánicos para controlar la mosca blanca en el cultivo de melón, se evaluó la efectividad de dos productos orgánicos en relación a un testigo químico. Los productos se aplicaron una vez por semana y se tomaron datos de campo dos días después de cada aplicación. Los dos tratamientos botánicos presentaron numéricamente los mayores valores de efectividad sobre Bemisia tabaci vrs el químico; existiendo estadísticamente diferencia significativa entre los tratamientos.

El tratamiento Neem $X$ es más efectivo y tampoco afecta la fenología de las plantas en comparación al testigo Rescate; en cambio el Neem (Azadirachta indica) no ha sido el primero de los insecticidas botánicos utilizados comercialmente, pero ha tenido un alto impacto en un número importante de cultivos entre ellos el melón (Cucumis melo).

Palabras Clave: Plagas; Azadirachtina; insecticidas botánicos; Bemisia tabaci. Neem

\section{ABSTRACT}

In order to identify and select botanical products to control white flies in the melon cultivation, the effectiveness of two organic products in relation to a chemical indicator was evaluated. The products were applied once a week and data was collected two days after each application. The two botanical treatments presented the highest numerical values in comparison to Bemisia tabaci vs the chemical ingredient, and this resulted in a significant statistical difference between treatments.

The treatment Neem $X$ is a more effective and does not affect the phenology of plants in comparison to Rescue control, but instead the Neem (Azadirachta indica) has not

\footnotetext{
Universidad Nacional Autónoma de Honduras. Centro Universitario Regional del Litoral Pacífico. Departamento de Agroindustria. Carrera de IngenieríaAgroindustrial.

* Universidad Nacional Autónoma de Honduras. Centro Universitario Regional del Litoral Pacífico. Departamento de Agroindustria. Carrera de Ingeniería Agroindustrial. Asesora. carimarroquin@yahoo.es
} 
been the first botanicar insecticide commercially used, but it has had a high impact in the crops including melón. (Cucumis melo).

Keywords: Pests, Azadirachtin, botanical insecticides, Bemisia tabaci, Neem. 


\section{INTRODUCCIÓN}

En busca de nuevas alternativas ecológicas para el control de plagas y reemplazar así los productos químicos, aparecen los insecticidas botánicos ofreciendo seguridad para el medio ambiente y una eficiente opción agronómica. (Borembaum, 1989).

Muchas plantas son capaces de sintetizar metabolitos secundarios que poseen propiedades biológicas con importancia contra insectos plagas. (Matthews, 1993; Enriz, 2000; Calderón, 2001; Céspedes, 2001; González-Coloma; 2002). El Neem tiene un alto poder insecticida. El nombre científico del árbol de Neem es Azadirachta, indica A.Juss, pertenece a la familia Meliacea, también conocida por su nombre común Margosa y Nimba. Los principales componentes del Neem son: triterpenoides o limonoides, azadirachtin, nimbin, salannin; con efectos específicos en las diferentes fases de crecimiento de los insectos.

Siendo la más importante la azadiractina y además de biodegradable resulta bastante eficaz; es tan potente que una simple señal de su presencia previene a algunos insectos, incluso hasta tocar las plantas, actuando como repelente, antialimentaria y antihormonal de insectos plaga y antiprotozoica. Este extracto produce una serie de efectos sinérgicos alterando el desarrollo, esterilización, alteración de apareamiento, y la inhibición del oviposor en insectos. La mosca blanca es un insecto-plaga, perteneciente al orden homóptera y a la familia Aleyrodidae.

Debido a su alta y rápida capacidad reproductiva, a la gran variedad de plantas hospederas cultivadas y silvestres, a las condiciones climáticas cálidas que favorecen su reproducción, así como a sus hábitos de vida característicos, se originan altas poblaciones que causan daños de importancia económica, que afectan el normal desarrollo de las plantas, así como la calidad del producto a cosechar.

Esta situación, unida a su difícil control, en especial al realizado mediante insecticidas químicos, ha llevado a establecer un enfoque de control más global, combinando adecuadamente todas las medidas de control disponibles dentro del manejo integrado de plagas (MIP).

Agroindustriales Los Prados, está produciendo melón (cantaloupe) en un lapso de tiempo de 54 días y para ello esta proporcionando buenos rendimientos, aplicando controles de insecticidas, mejorando sus cultivos y obteniendo producto de 
calidad, pero presentando en todo el ciclo del cultivo daños directos e indirectos causados por mosca blanca. Por lo tanto, para controlar la plaga utilizan el insecticida Rescate ${ }^{\circledR}$ ya que posee una alta acción sistémica, que actúa por contacto e ingestión, afectando el receptor acetil Colina Nicotínico de la membrana post sináptica en el sistema nervioso de los insectos.

El cultivo de melón (Cucumis melo) es una planta anual, originaria de Asia occidental y África. Se cultiva para el aprovechamiento de los frutos que poseen un sabor delicioso, delicado y apetecido presentando diferentes tipos de pulpa desde color naranja, verde y salmón. Se evaluaron dos extractos botánicos (Neem comercial, Neem artesanal) y un producto sintético (Rescate) para control de mosca blanca en cultivo de melón.

\section{MÉTODOS}

\section{Diseño}

Es una investigación experimental de bloques al azar, analítico, observacional, descriptivo y de corte transversal.

\section{Población y muestra}

Cada unidad experimental constará de $25 \mathrm{~m}$, tomando en cuenta $21 \mathrm{~m}$ de área útil y los bloques separados a 1.8 metros, considerando para recolección de muestra el efecto de borda. Será subdividido en 18 camas que consta de 130 plantas a una distancia de $0.5 \mathrm{~m}$.

\section{Entorno}

El estudio se realizó en el departamento de Choluteca en el municipio de Namasigue, aldea El Obraje, kilómetro 19, en plantaciones Agroindustriales Los Prados, en el lote El Bonilla.

\section{INTERVENCIONES}

\section{Manejo del experimento}

El experimento se realizó utilizando 2 productos botánicos Neem comercial (Neem X), Neem artesanal) como tratamientos y un químico de testigo (Rescate), usando tres repeticiones por tratamiento, en un área de $3,960 \mathrm{~m}^{2}$ subdividido en 18 camas que constan de 130 plantas a una distancia de $0.5 \mathrm{~m}$. 


\section{Variables a evaluar}

\section{Incidencia de mosca blanca}

Se cuantificó el número de plantas por surco, con o sin presencia de mosca blanca para determinar el porcentaje de las plantas afectadas. Las lecturas se tomaron a los seis días después del trasplante y cada seis días después de cada aplicación.

\# de plantas $x$ tratamiento / \# total de plantas $\times 100=$ promedio de plantas con incidencia de mosca.

\section{Eficiencia de control de adulto de mosca blanca}

La eficiencia de los productos evaluados se determinó contando las moscas blancas 2 horas antes de efectuar las aplicaciones, así como 48 horas después, se muestrearon las plantas por parcelas.

\section{Descripción del experimento}

Los tratamientos consistirán en tres insecticidas (dos botánicos y uno sintético) diferentes, los cuales serán de tres repeticiones. La distribución de los bloques será realizada al azar. Cada unidad experimental constará de $25 \mathrm{~m}$, tomando en cuenta $21 \mathrm{~m}$ de área útil y los bloques separados a 1.8 metros, considerando para recolección de muestra el efecto de borda.

Antes de las aplicaciones se realizaron conteos para conocer la incidencia de la mosca blanca (Bemisia tabaci) y posteriormente se aplicó el producto a los tratamientos asignados con una bomba de mochila con capacidad de 20 litros en sus cuatro aplicaciones. Las siguientes oportunidades se fumigó con bomba de motor con capacidad de 18 litros debido a la altura del follaje requiriendo de mayor presión. 48 horas después se tomaron datos de la efectividad de cada tratamiento tomando en cuenta la muestra de 36 plantas por 6 repeticiones por tratamiento debido al efecto de borda.

\section{RESULTADOS Y DISCUSIÓN}

\section{Incidencia de mosca blanca}

En el caso de los resultados obtenidos de las aplicaciones de los insecticidas botánicos y un insecticida sintético que se emplearon, muestran estadísticamente 
diferencia significativa $(p<=0.05)$ entre los tratamientos para el número de plantas infestadas de mosca blanca.

En la tercera y cuarta aplicación aumentó la presencia de la mosca blanca debido al tratamiento inadecuado del agua siendo su $\mathrm{pH}$ de 6.9 , lo que para un adecuado uso debía ser un pH 5.5, considerando que era el segundo ciclo de cultivo de melón siendo él más complicado. Otro factor que influyó en la incidencia fueron las altas temperaturas, la velocidad del viento y algunas lluvias.

\section{Mortalidad de mosca blanca y su control}

Al evaluar el número de moscas muertas por tratamiento muestran estadísticamente diferencias significativas $(p<=0.05)$ presentando mayores resultados en Neem $X$ en comparación con los otros tratamientos. Existe una diferencia estadísticamente significativa $(p<=0.05)$ entre los tratamientos puesto que el Rescate ha sido de uso frecuente y sin ningún tratamiento para controlar el $\mathrm{pH}$ del agua manteniéndose en rangos 6.9 - 7.5. En la mayoría de los casos los insecticidas químicos de uso frecuente ocasionan el resurgimiento y resistencia de plagas.

\section{CONCLUSIONES}

- El tratamiento Neem X es más efectivo y tiene la ventaja que no provoca estrés al cultivo por ser fisiológicamente afín y no afecta la fenología de las plantas en comparación al testigo Rescate; en cambio el Neem (Azadirachta indica) no ha sido el primero de los insecticidas botánicos utilizados comercialmente, pero ha tenido un alto impacto en un número importante de cultivos entre ellos melón (cucumis melo).

- La incidencia de plagas ocasiona limitantes en las cosechas. Su control debe ser compatible con la naturaleza con el propósito de conservar los ecosistemas y realizar una producción racional, pero, sin descuidar la calidad del producto final.

\section{BIBLIOGRAFÍA}

- Biol. Maggi Maria. Nim. acceso 10 de febrero 2010. Disponible en: www.fao.or/teca/es/content/el-nim-azadirachta-indica

- Castro Diego. El árbol de Neem. Acceso: 26 de febrero. Disponible en: 
www.canoma.net.

- Emaqqi. Insecticidas Naturales. Acceso 26 de febrero. Disponible en: www.monografias.com/insecticida-naturales.

- Fernández Raquel. El Nim. Un insecticida fabricado por la naturaleza. Acceso 20 de febrero. Disponible en: www.envio.org.ni/articulo/877.

- InfoAgro. El cultivo de melón. Acceso 15 de febrero. Disponible en: http://www.infoagro.com/frutas/frutas_tradicionales/melon.htm

- INFOJARDIN. Mosca blanca, acceso 18 de febrero, disponible en: /larticulos.infojardin.com/PLAGAS_Y_ENF/PLAGAS/Mosca_blanca.htm

- Menjivar,R. acceso 10 de febrero. Disponible en: www.scribd.com/ doc/22076794/caracterizacion-fisicoquimica-de-los-extracto-de-lasemilla-delarbol-del-neem

- Q.B Rubio Luis. ZOE Tecno- Campo- El Neem o Nim. Acceso 20 de febrero. Disponible en: www.azoetecnocampo.com/actualidad/actneem.

- Szanka y Lena. Neem, Azadirachta indica A. Juss, acceso 10 de febrero. Disponible en: www.salud.bioctica.org/neem.htm

- Wesley Daniel. Protección Natural de Cultivos. Acceso 10 de febrero. Disponible en: www./helsint.com/agricultura.html 